\title{
KEBUTUHAN MESIN PERTANIAN DAN TENAGA UNTUK MEKANISASI USAHATANI PADI SKALA KECIL DI KABUPATEN KAMPAR, PROVINSI RIAU
}

\section{Farm Machinery and Power Requirements for mechanizing Small-scale Rice Farming in Kampar Regency, Riau Province}

\author{
Ujang Paman, Khairizal, dan Hajry Arief Wahyudy \\ Program Studi Agribisnis, Fakultas Pertanian, Universitas Islam Riau \\ Jl. Kaharuddin Nasution No. 113 P. Marpoyan, Pekanbaru, Riau 28284, Indonesia. \\ E-mail: pamanu@agr.uir.ac.id
}

\begin{abstract}
Farm machinery is one of the important power sources to carry out farm operations today. The availability of farm power in adequate number is prerequisites for providing enough power in perform rice farming operation. This paper attempts to evaluate the farm machinery and power requirement for performing operations of small-scale rice farming in Kampar Regency, Riau Province. Data were obtained from field survey in 15 districts from 21 districts of Kampar Regency. Village surveys were chose for each selected district which are rice production center and farm machines have been used in working rice farm operations. Samples were purposively selected and consisted of 30 farmers, 5 extension staffs and 20 machine operators. They were interviewed to collect field data on September 2015 by using questionnaires. The results show that the number of farm machinery was not sufficient to fulfill requirement and provide enough power for farm operations. From farm machinery available, it provided power about $0.61 \mathrm{hp}^{-\mathrm{ha}^{-1}}$, while minimum power required for efficient rice farming is about $0.8 \mathrm{hp}_{\mathrm{ha}} \mathrm{h}^{-1}$. The results suggest that the number and type of farm machinery must be increased with financial support and involve private sectors.
\end{abstract}

Keywords: Farm machinery, power requirements, small-scale rice farming.

\begin{abstract}
ABSTRAK
Mesin pertanian merupakan salah satu sumber tenaga (power) penting untuk melaksanakan operasi pertanian sekarang ini. Keberadaan masin pertanian dalam jumlah yang memadai penting untuk menyediakan tenaga yang cukup untuk mengerjakan operasi usahatani. Pnelitian ini mencoba mengevaluasi kebutuhan mesin pertanian dan tenaga untuk melaksanakan operasi usahatani padi sawah skala kecil di Kabupaten Kampar. Data diperoleh melalui survey lapangan di 15 kecamatan dari 21 kecamatan yang ada di Kabupaten Kampar. Di setiap kecamatan diambil satu desa yang merupakan sentral produksi padi dan telah mengunakan mesin pertanian. Wawancara telah dilakukan terhadap sampel yang terdiri dari petani, penyuluh pertanian lapangan dan operator mesin. They telah dipilih secara sengaja sebagai sampel masing-masing sebanyak 30 petani, 5 penyuluh dan 20 operator pada bulan September 2015. Jumlah mesin pertanian yang ada belum cukup untuk memenuhi kebutuhan dan menyediakan tenaga sesuai dengan yang dibutuhkan. Dari jumlah mesin pertanian yang ada tersebut, baru tersedia tenaga sebanyak $0.61 \mathrm{hp} \cdot \mathrm{ha}^{-1}$, sedangkan kebutuhan minimum sebesar 0.8 hp.ha $^{-1}$. Hasil ini menyarankan agar jumlah dan tipe mesin pertanian yang dibutuhkan harus ditingkatkan dengan dukungan keuangan dan melibatkan pihak swasta.
\end{abstract}

Keyword: Mesin pertanian, Kebutuhan tenaga, Usahatani padi skala kecil

\section{PENDAHULUAN}

Sektor pertanian sudah mengalami transformasi dan modernisasi di negara di berbagai belahan dunia. Mekanisasi pertanian merupakan elemen penting dalam tranformasi dan moder- nisasi sistem pertanian tersebut (Verma and Tripathi, 2016) dan memegang peranan kunci dalam memperbaiki dan meningkatkan produksi pertanian terutama di negara-negara sedang berkembang (Mehta et al., 2014). 
Mekanisasi pertanian merupakan penggunaan teknologi mekanis dalam berbagai operasi usahatani (Iqbal et al, 2015) dan kemudian mengambil alih tenaga manusia dan ternak dalam proses produksi pertanian. Selanjutnya, mekanisasi pertanian dapat pemicu perubahan teknologi melalui adopsi sumber tenaga non manusia untuk mengerjakan operasi usahatani (Diao et al., 2016). Selanjutnya, tenaga (power) merupakan salah satu imput yang sangat berharga dalam sistem produksi pertanian (Khambalkar et al., 2010). Perubahan teknologi pertanian dari tenaga manusia atau/dan ternak ke tenaga mesin atau mekanis dalam pertanian akan cenderung meningkatkan permintaan mesin oleh petani. Power dan mesin merupakan bagian integral dari pertanian moeren, sehingga perkembangan penggunaan mesin pertanian dalam pertanian moderen menciptakan permintaan baru oleh petani (Jacobs and Harrel, 1983).

Mekanisasi usahatani khususnya di negara-negara berkembang diterapkan dalam level yang berbeda (Binswanger, 1984). Di Indonesia, mekanisasi pertanian sekarang ini masih dalam tahap perkembangan dan kecepatan perkembangannya masih relatif lambat dan berbeda diantara provinsi atau daerah. Lambatnya proses perkembanan tersebut disebabkan oleh beberapa hambatan antara lain faktor sosial ekonomi, teknik dan kelembagaan (Hendriadi, 2009). Konsekuensinya, level mekanisasi di Indonesia masih relatif rendah sampai tinggi dengan rata-rata sekitar $30 \%$ (Handaka 2005). Di Provinsi Riau, Paman et al., (2016) telah melaporkan bahwa tingkat penerapan mekanisasi pertanian baru sekitar 28\% pada tahun 2013. Rendahnya level mekanisasi di Provinsi Riau tersebut dapat disebabkan oleh kurangnya jumlah dan penerapan mesin pertanian di tingkat petani. Selama periode 2009-2013, jumlah mesin pertanian utama di Provinsi Riau antara lain traktor tangan, pompa air, mesin perontok dan mesin penggiling padi telah meningkat dari 5.610 unit menjadi 6.371 unit atau naik sekitar $6 \%$ per tahun (Dinas Pertanian dan Peternakan Provinsi Riau, 2014).

Menurut Handaka (2005), perkembangan mekanisasi pertanian di Indonesia akan mengikuti dan sangat tergantung pada proses perkembangan ekonomi nasional. Dukungan Pemerintah telah memberi contribusi yang signifikan terhadap peningkatan penggunaan mesin pertanian di kalangan petani melalui terutama pembiayaan untuk pembelian mesin. Ini artinya bahwa perbaikan kondisi ekonomi pertani sebagai hasil dari pertumbuhan ekonomi nasional akan cenderung untuk menigkatkan permintaan mesin pertanian yang mempunyai tenaga dan efisiensi yang tinggi. Mesin pertanian juga dibutuhkan untuk memenuhi kebutuhan energi dalam melaksanakan berbagai operasi/pekerjaan dalam usahatani. Studi sebelumnya telah menyimpulkan bahwa untuk mencapai hasil yang optimum dan efisien diperlukan input tenaga sekurang-kurangnya sebesar 0,8 hp. ha ${ }^{-1}$ (Jain, 1979).

Selanjutnya, permintaan mesin pertanian tergantung pada beberapa faktor antara laini intensitas sistem pertanian, ketersediaan pelengkap teknologi dan kapasitas penggunaan mesin (Diao et al., 2016). Kecukupan ketersediaan energi mekanis, dan efektif dan efisien penggunaan mesin menjadi prasyarat untuk perbaikan produksi pertanian (Himanshu et al., 2012). Tujuan peneitian ini adalah untuk mengevaluasi permintaan mesin pertanian dan kebutuhan tenaga untuk melaksanakan operasi usahatani padi lahan kecil di Kabupaten Kampar. Pelitian ini menjadi penting karena dapat menemukan kebutuhan mesin pertanian dan energi (power) sebagai sumber tenaga selain manusia agar operasi pertanian bisa lebih efektif dan efisien.

\section{BAHAN DAN METODE}

Penelitian ini menggunakan metode survei yang berlokasi di Kabupaten Kampar yang merupakan salah satu kabupaten dari 12 kabupaten/kota di Provinsi Riau. Kabupaten ini terdiri dari 21 kecamatan dan 250 kelurahan/ desa dengan total area seluas 11.289,28 $\mathrm{km}^{2}$. Total penduduk kabupaten ini sebanyak 371.449 jiwa dengan kepadatan 30 jiwa $/ \mathrm{km}^{2}$. Kabupaten Kampar merupakan kabupten yang sangat penting di Riau sebab merupakan salah satu daerah sentral produksi padi di Province ini. Untuk meningkatkan produksi padi sawah, penerapan mekanisasi pertanian, khususnya mesin pertanian menjadi periortas. Mesin pertanian telah digunakan di daerah ini selama 10 tahun belakangan dan cenderung meningkat dari tahun ke tahun. Akan tetapi skala usahatani padi sawah di daerah ini sebagian besar skala subsisten. 


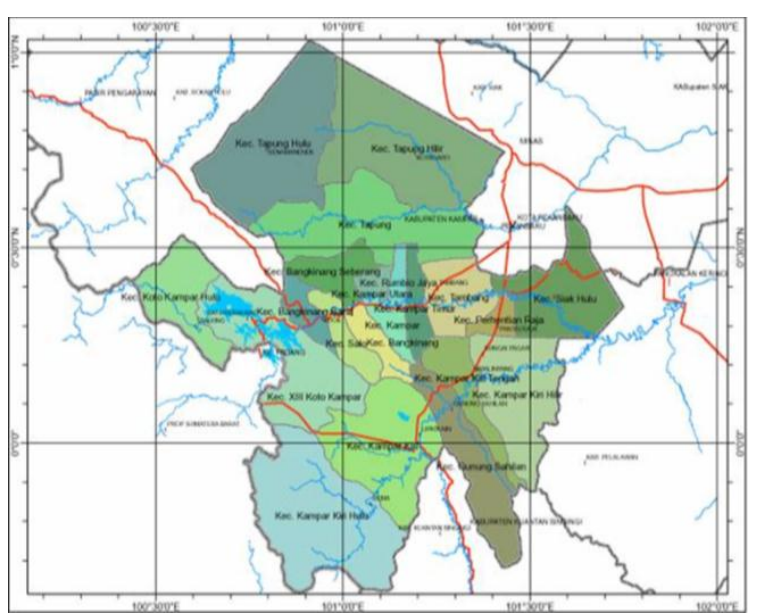

Gambar 1. Peta Kabupaten Kampar

Penelitian ini telah dilakukan di 15 kecamatan yang dipilih secara sengaja dari 21 kecamatan yang terdapat di Kabupaten Kampar. Kecamatan terpilih didominasi oleh sentral produksi padi sawah semi irigasi atau sawah tadah hujan. Sawah tadah hujan merupakan jenis sawah terluas di Kabupaten Kampar. Populasi penelitian ini adalah petani, penyuluh pertanian lapangan dan operator mesin. Sampel diambil secara sengaja sebanyak 30 petani, 5 penyuluh dan 20 operator. Wawancara dengan sampel dilakukan pada bulan September 2015 untuk mengumpulkan data lapangan.

Data yang dikumpulkan terdiri dari data primer and sekunder. Data tersebut dikumpulkan dengan menggunakan kuesioner yang telah disiapkan terlebih dahulu. Data yang dikumpulkan terdiri dari luas areal tanaman padi, produksi dan produktivitas, jenis dan jumlah mesin, dan luas kerja mesin per musim. Data sekunder diperoleh dari laporan tahunan Dinas Pertanian Tanaman Pangan dan Hortikultura dan kantor statistic baik di tingkat provinsi maupun kabupaten. Data kemudian dianalisis dengan menggunakan pendekatan deskriptif kuantitatif.

\section{HASIL DAN PEMBAHASAN}

\section{Luas Areal dan Produksi Padi}

Tanaman padi bukan merupakan tanaman utama di Kabupaten Kampar. Akan tetapi, padi merupakan tanaman penting sebab beras merupakan makanan pokok bagi masyarakat. Padi di Kabupaten Kampar umumnya ditanam pada sawah semi irigasi dan tadah hujan dengan $1-2$ musim tanam per tahun tergantung pada kondisi iklim. Gambar 1 menggambarkan that areal padi sawah tidak bisa diusahakan secara keseluruhan setiap tahun karena kekurangan tenaga kerja, modal dan kasus kekeringan. Areal padi yang diusahakan terluas pada tahun 2011 dan kumudian menurun mencapai paling kecil pada tahun 2015. Jumlah produksi padi sawah berfluktuasi setiap tahun selama periode 2009-2015. Produksi tertinggi terjadi pada tahun 2012 sebesar 52.154 ton dan terendah pada pada tahun 2014 sebesar 29.666 ton. Fluktuasi produksi padi sangat tergantung pada kondisi iklim lokal. Pada tahun 2014, Elnino melanda Indonesia yang menyebabkan lebih panjang musim kering/kemarau dan mengakibat menurun/kehilangan produksi.

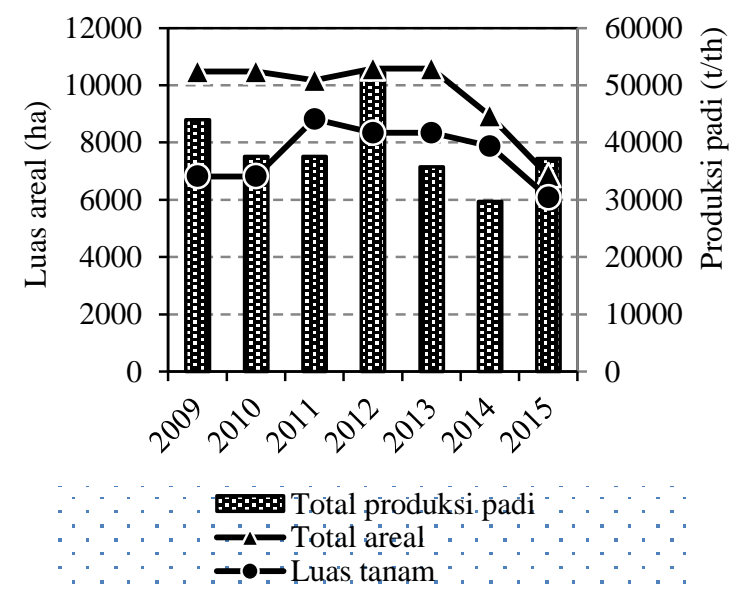

Sumber: Dinas Pertanian dan Peternakan Provinsi Riau, 2016

Gambar 2. Total Areal dan Produksi Padi di Kabupaten Kampar selama periode 2009-2015

\section{Ketersediaan mesin pertanian dan Penggu- naan dan Permiiintaan}

Usahatani padi di Kabupaten Kampar didominasi oleh usahatani skala kecil, sehingga jenis mesin kecil sangat popular digunakan petani di areal tersebut. Penggunaan mesin pertanian adalah untuk melaksanakan pekerjaan terutama operasi yang banyak membutuhkan tenaga fisik seperti pengolahan tanah, irigasi, perontokan dan penggilingan. Karena itu, jenis mesin pertanian yang tersedia di areal tersebut meliputi traktor tangan, pompa air, mesin perontok, dan mesin penggiling padi. Pompa air merupakan jenis mesin terbanyak dan tercatat sebanyak 254 unit (38\%) tahun 2015 
Tabel 1. Perkembangan Mesin Pertanian di Kabupaten Kampar Selama Periode 2009-2015

\begin{tabular}{lrrrrrrr}
\hline \multirow{2}{*}{ Jenis mesin } & \multicolumn{7}{c}{ Tahun } \\
\cline { 2 - 7 } & 2009 & 2010 & 2011 & 2012 & 2013 & 2014 & 2015 \\
\hline Traktor besar/medium & 0 & 0 & 0 & 5 & 4 & 8 & 8 \\
Traktor tangan & 103 & 155 & 165 & 160 & 165 & 165 & 196 \\
Pompa air & 91 & 181 & 175 & 190 & 211 & 211 & 254 \\
Mesin perontok & 22 & 35 & 27 & 37 & 37 & 37 & 133 \\
Mesin Penggiling & 88 & 69 & 69 & 61 & 61 & 64 & 81 \\
Combine harvester & 0 & 0 & 0 & 0 & 0 & 0 & 2 \\
Reaper & 0 & 0 & 0 & 0 & 0 & 1 & 1 \\
Total & 307 & 440 & 436 & 453 & 478 & 486 & 675 \\
\hline
\end{tabular}

Sumber: Dinas Pertanian dan Peternakan Provinsi Riau 2016

dan diikuti oleh traktor tangan (29\%) dan mesin perontok padi $(20 \%)$ pada tahun yang sama. Sementara, mesin pemanen berupa combine harvester dan reaper masih dalam tahap pengenalan kepada petani di lokasi survei. Perkembangan jenis mesin pertanian di atas selama periode 2009-2015 disajikan dalam Tabel 1 dan pada Gambar 2. Secara umum, selama periode tersebut, jumlah mesin pertanian telah meningkat sekitar $15 \%$ per tahun. Pertumbuhan tertinggi terdapat pada mesin perontok yang mencapai $55 \%$ per tahun, kemudian diikuti oleh pompa air (23\%) dan traktor tangan (13\%). Selanjutnya, mesin penggiling padi meningkat hanya $1 \%$ per tahun. Mesin ini biasanya digunakan petani sepanjang tahun dengan perbedaan volume kerja setiap bulannya (Paman et al., 2016).

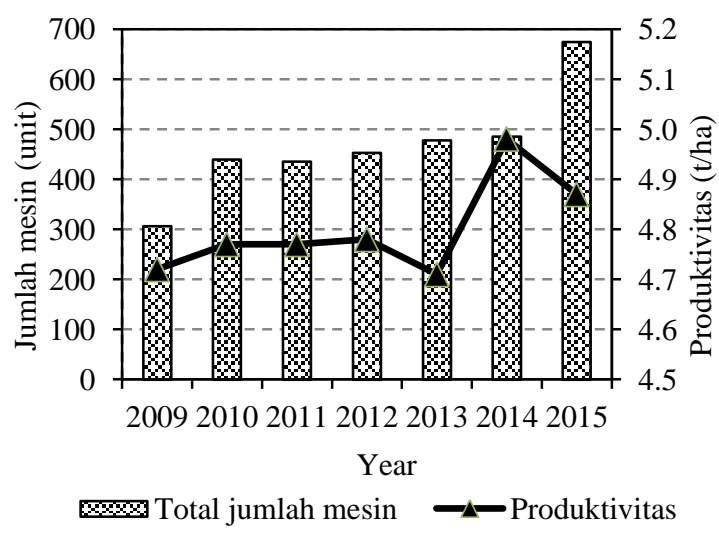

Sumber: Dinas Pertanian dan Peternakan Provinsi Riau, 2016

Gambar 2. Jumlah Ketersediaan Mesin Pertanian dan Produktivitas Padi Sawah selama Periode 2009-2015
Gambar 2 menunjukkan perkembangan mesin pertanian dan produktivitas padi sawah selama perode 2009 - 2015. Jumlah total mesin pertanian meningkat dari 307 unit tahun 2009 menjadi 675 unit tahun 2015 dengan peningkatan per tahun seebesar 15\%. Peningkatan jumlah mesin pertanian tidak menunjukkan pengaruh yang berarti pada produktivitas padi sawah selama periode tersebut. Walaupun jumlah mesin pertanian meningkat signifikan selama periode 2009-2015, produktivitas meningkat lebih rendah selama periode yang sama dan bahkan cenderung menurun pada tingkat yang paling rendah yaitu $0.5 \%$ pada tahun 2013 . Selanjutnya, ketika jumlah mesin pertanian meningkat pada tingkat tertinggi tahun 2015, produktivitas padi cenderung menurun dan ini lebih rendah dari tahun 2014. Kondisi ini mungkin disebabkan masih belum cukup memadainya jumah mesin pertanian di daerah tersebut. Peningkatan pasokan mesin pertanian diperlukan untuk mencapai jumlah yang cukup memadai dan kemudian memberikan efek signifikan pada produktvitas padi sawah.

Gambar 3 memperlihatkan bahwa kebutuhan berbagai jenis mesin pertanian di Kabupaten Kampar tahun 2015. Kebutuhan yang paling tinggi adalah traktor tangan dan yang paling sedikit adalah mesin penggiling padi. Hal ini akan menyebabkan perrmintaan traktor tangan menjadi lebih tinggi dibanding dengan jenis mesin lainnya. Tingginya kebu-tuhan ini disebabkan bahwa penggunaan mesin pertanian untuk pengolahan tanah sudah semakin tinggi terutama mesin pertanian untuk pengolahan tanah. 


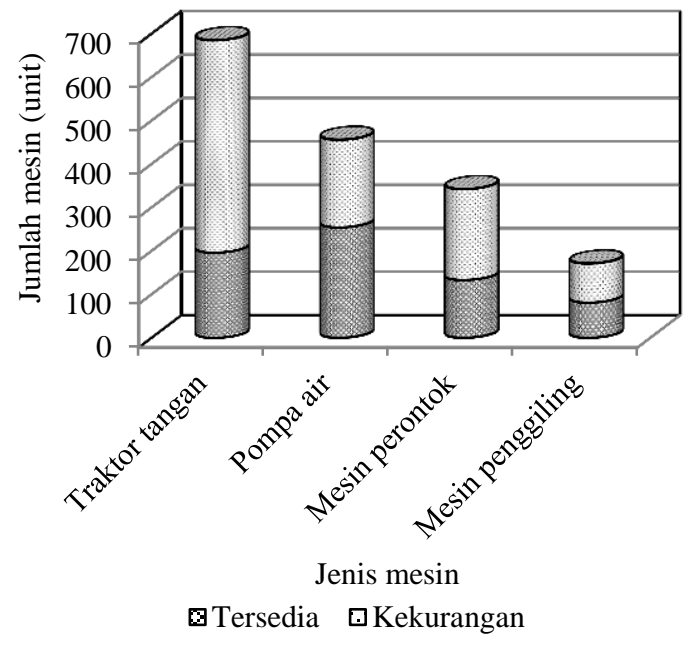

Gambar 3. Kebutuhan, Ketersediaan dan Kekurangan Mesin Pertanian Tahun 2015

Mesin pertanian yang digunakan oleh petani kecil di Kabupaten Kampar umumnya dimiliki secara individu dan kelompok tani yang dikenal dengan nama usaha pelayanan jasaa alsintan (UPJA). Dari Gambar 4 terlihat bahwa kepemilikan secara individu dominan di Kabupaten Kampar dan mesin mereka dibeli sendiri dari dealer. Mesin pertanian yang dimiliki oleh kelompok UPJA merupakan mesin yang dibantu langsung oleh pemerintah melalui program pengembangan mekanisasi pertanian. Mesin pertanian yang dibeli pemerintah didistribusikan kepada kelompok tani untuk dikelola dalam bentuk usaha penyewaan jasa alsintan (UPJA) dan menyediakan pelayan untuk anggota kelompok tani (Paman et al., 2014). Mesin pertanian yang dikelola petani secara individu digunakan sendiri dan kelebihan kapasitas biasanya ditawarkan kepada petani lain untuk disewa jasanya. Biaya sewa berbeda antara kelompk UPJA dan individu, dan kelompok UPJA menawarkan sewa lebih rendah dibandingkan dengan petani individu. UPJA merupakan penggunaan alternatif penggunaan mesin untuk mencapai tingkat keekonomian dalam pengelolaan mesin dan dari usaha ini dapat memberikan pendapatan tambahan dari penyediaan pelayan tersebut. Bisnis penyewaan mesin pertanian ini menguntungkan secara ekonomi baik dikelola secara individu (Paman et al., 2010) maupun dikelola di bawah kelompok UPJA (Paman et al., 2016).

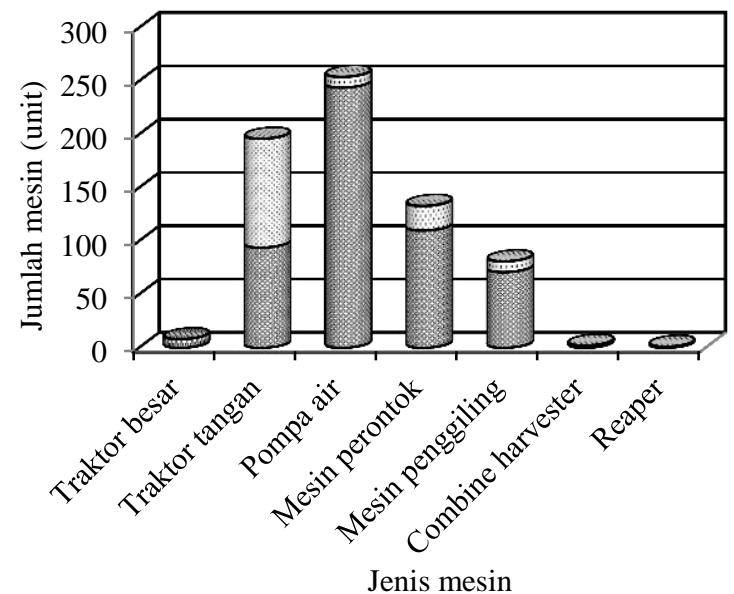

๑Individu $\mathbf{0}$ Kelompok

Gambar 4. Sistem Kepemilikaan Mesin Pertanian di Kabupaten Kampar

Sebagaimana telah dijelaskan di atas, jumlah mesin pertanian yang tersedia masih belum memadai untuk meningkatkan produktivitas usahatani padi secara signifikan di Kabupaten Kampar. Gambar 5 menunjukkan perkembangan hasil kerja per musim per mesin di Kabupaten Kampar selama periode 2009 2015. Selama periode tersebut, mesin perontok dan mesin penggiling menunjukkan hasil kerja paling kecil per mesin. Namun demikian, kepadatan kedua mesin tersebut meningkat pada tahun 2015 disebabkan meningkatnya jumlah mesin pertanian di areal tersebut. Konsekuensinya, hasil kerja per mesin sebesar 129 dan 41 ha untuk mesin perontok dan mesin penggiling padi. Ini artinya bahwa kepadatan mesin pertanian meningkat mengikuti meningkatnya jumlah mesin yang ada. Sementara itu, traktor tangan dan pompa air tidak menunjukkan peningkatan secara signifikan selama periode yang sama. Namun secara umum, kepadatan mesin pertanian belum cukup untuk mencapai mekanisasi secara penuh (full mechanization) untuk operasi usahatani padi. Herdt (1983) mengatakan bahwa untuk mencapai tahap mekanisasi secara penuh diperlukan sebanyak 100 traktor tangan per 1000 ha (atau 10 hektar per traktor). Hasil ini menunjukkan bahwa jumlah traktor tangan yang tersedia di Kabupaten Kampar tidak cukup untuk mencapai tahap mekanisasi secara penuh (full mechanization). 


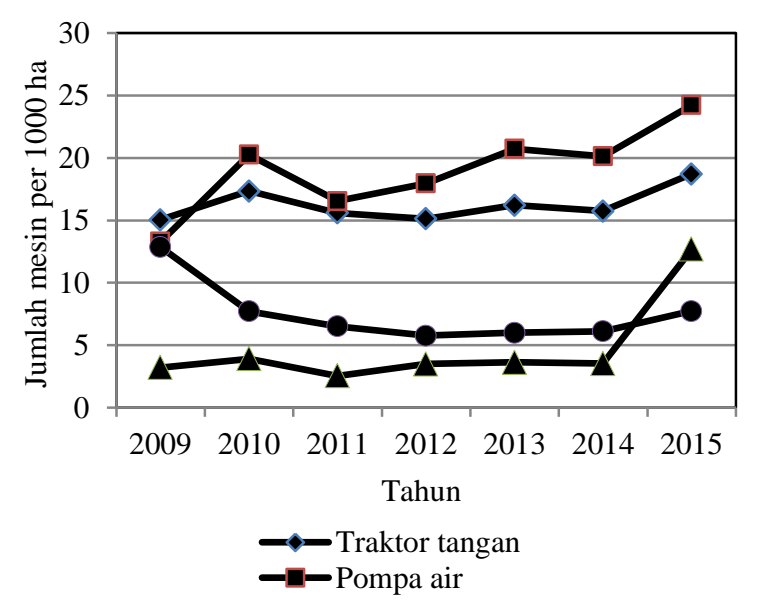

Gambar 5. Kepadatan Mesin Pertanian Selama Periode 2009-2015.

\section{Kebutuhan Tenaga dalam Usahatani}

Ketersediaan tenaga dalam usahatani padi di Kabupaten Kampar dinyatakan sebagai jumlah tenaga per hektar $\left(\mathrm{hp} \cdot \mathrm{ha}^{-1}\right)$. Ketersediaan tenaga tersebut secara langsung berkaitan dengan jumlah tenaga yang dibutuhkan untuk melaksanakan operasi usahatani. Ketersediaan tenaga mesin selama periode 2009-2015 di Kabupaten Kampar disajikan pada Gambar 6. Total jumlah tenaga mesin meningkat dari $1.566 \mathrm{hp}(1.168 \mathrm{~kW})$ menjadi $6.356 \mathrm{hp}(4.740$ $\mathrm{kW})$ dengan tingkat pertumbuhan sekitar $29 \%$ per tahun. Tenaga mekanis ini bersumber dari traktor besar/menengah, traktor tangan, pompa air, mesin perontok, mesin penggiling padi, combine harvester dan reaper. Pompa air memberikan kontribusi terbesar kemudian diikuti oleh traktor tangan dan mesin penggiling padi. Jumlah tenaga yang tersedia sangat tergantung pada jumlah mesin pertanian yang ada. Berdasarkan ketersediaan tenaga, tenaga yang tersedia per hektar juga meningkat dari 0,23 hp.ha ${ }^{-1}\left(0,17 \mathrm{~kW} \cdot \mathrm{ha}^{-1}\right)$ tahun 2009 menjadi 0,61 hp.ha ${ }^{-1}\left(0,45 \mathrm{~kW} \cdot \mathrm{ha}^{-1}\right)$ pada tahun 2017 dengan tingkat pertumbuhan sebesar $21 \%$ per tahun. Jumlah ini belum cukup untuk mencapai produksi padi secara optimal yang membutuhkan tenaga minimal 0,8 hp.ha ${ }^{-1}$ (Jain, 1979). Hasil ini menyarankan bahwa jumlah mesin pertanian harus ditingkatkan untuk memenuhi kebutuhan tenaga (power) yang cukup untuk operasi usahatani padi di Kabupaten Kampar. Kecukupan tenaga terutama yang bersumber dari tenaga mesin sangat membatu dalam memeuhi kekurangan tenaga terutama pada saat penggunaan puncak

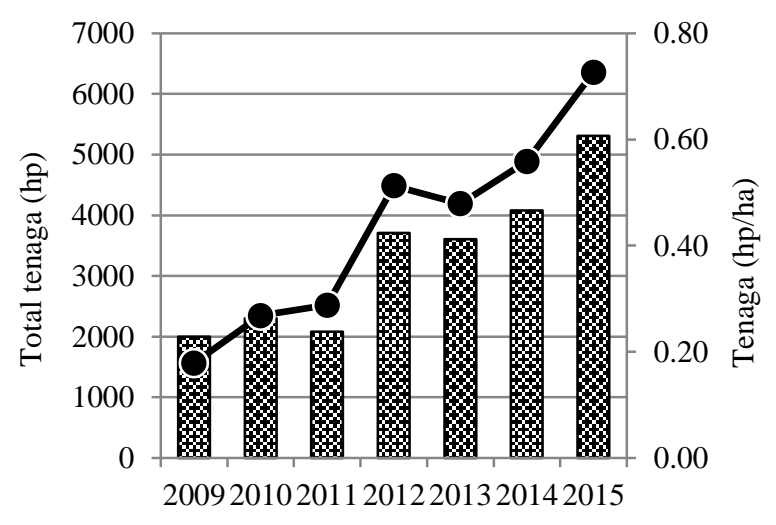

Tahun

KXKXX Ketersediaan tenaga (hp/ha)

-•-Total tenaga tersedia (hp)

Gambar 6. Jumlah Tenaga Tersedia pada Usahatani Selama Periode 2009-2015

\section{KESIMPULAN}

Jenis mesin pertanian yang banyak diminta dan digunakan petani kecil terdiri dari hand traktor, pompa air, mesin perontok dan mesin penggiling (RMU). Mesin-mesin tersebut sangat cocok dengan kondisi lahan, daya beli dan keterampilan teknis yang dimiliki petani. Jumlah mesin pertanian tersebut meningkat per tahun selam periode 2009-2015. Namun jumlah tersebut belum cukup untuk memenuhi kebutuhan dan menyediakan tenaga sesuai dengan yang dibutuhkan. Kebutuhan tertinggi adalah traktor tangan sebanyak 685 unit dan terkecil adalah mesin penggiling padi sebanyak 171 unit. Dari jumlah mesin pertanian yang ada tersebut, baru tersedia tenaga sebanyak $0.61 \mathrm{hp} \cdot \mathrm{ha}^{-1}(0.45$ $\left.\mathrm{kW} \cdot \mathrm{ha}^{-1}\right)$, sedangkan kebutuhan minimum sebesar $0.8 \mathrm{hp} \mathrm{ha}^{-1}$. Dari hasil penelitian ini dapat disarankan bahwa tipe dan jumlah mesin pertanian harus ditingkatkan se-suai dengan yang dibutuhkan dengan dukungan keuangan dan melibatkan pihak swasta.

\section{DAFTAR PUSTAKA}

Binswanger, H. 1986. Agricultural Mechanization: A Comparative Historical Perspective. Research Observer, 1(1): 27-56.

Diao, X., J. Silver, and H. Takeshima. 2016. Agricultural Mechanization and Agricultural Transformation. International Food 
Policy Research Institute (IFPRI), Washington DC.

Dinas Pertanian dan Peternakan Provinsi Riau. 2014. Buku Seri Data Tanaman Pangan dan Hortikultura Tahun 2013. Pekanbaru.

Dinas Pertanian dan Peternakan Provinsi Riau. 2016. Buku Seri Data Tanaman Pangan dan Hortikultura Tahun 2015. Pekanbaru.

Handaka. 2005. Agricultural Engineering Research and Development in Indonesia: Challenge and Prospect toward Sustainable Agriculture and APCAEM Program. Paper Presented in APCAEM TC/GT Meeting in New Delhi, 21-24 November 2005. New Delhi.

Handaka. 2009. Towards Sustainable Agricultural Mechanization in Indonesia: A Conceptual Model of Innovation Technology. Technology Monitor. pp. 38-43.

Hendriadi, A. 2009. Country Report of Indonesia. Ministry of Agriculture, Republic of Indonesia, Jakarta.

Herdt, R. W. 1983. Mechanization of Rice Production in Developing Asian Countries: Perspective, Evidence, and Issues. In Consequences of Small-Farm Mechanization: International Rice Research Institute and Agricultural Development Council, Los Banos, Philippines. pp 1 13.

Himanshu S. K., S. Kumar, A. Kumar, and K. K. Gupta. 2012. Energy Economics Assessment of Crops in Traditional And Mechanized Farming. International Research Journal of Environment Sciences, 1(5), 27-34.

Iqbal, M. A., A. Iqbal, S. Afzal, N. Akbar, R. N. Abbas, and H. Z. Khan. 2015. In Pakistan, Agricultural Mechanization Status And Future Prospects. American-Eurasian Journal Agricultural \& Environment Sciences, 15(1): 122-128.

Jacobs, C. O. and W. R. Harrell. 1983. Agricultural Power and Machinery. McGrawHill, Inc. New York.
Jain, B. K. S. 1979. Tractors in Indian Agriculture - Their Place and Problem. Agricultural Mechanization in Asia, Africa, and Latin America, Autumn Issue, 31 34.

Khambalkar, V., J. Pohare, S. Katkhede. D. Bunde, and S. Dahatonde. 2010. Energy and Economic Evaluation of Farm Operations in Crop Production. Journal of Agricultural Science, 2(4): 191-200.

Mehta, C. R. N. S. Chandel, and T. Senthilkumar. 2014. Status, Challenges and Strategies for Farm Mechanization in India. Agricultural Mechanization in Asia, Africa, and Latin America, 45(4): 45-50.

Paman, U., S. Uchida, and S. Inaba. 2010. Economic Potential of Tractor Hire Business in Riau Province, Indonesia: A Case Study of Small Tractors for Small Rice Farms. Agricultural Engineering International: CIGR Journal, 12(1), 135142.

Paman, U., S. Inaba, and S. Uchida. 2014. Farm Machinery Hire Services for Small Farms in Kampar Regency, Riau Province, Indonesia. Applied Engineering in Agriculture, 30(5), 699-705.

Paman, U., S. Inaba, and S. Uchida. 2016. Economic Aspects of Machinery Hire Services Managed by Farmer Groups in Kampar Regency, Indonesia. Applied Engineering in Agriculture, 32(2): 169179.

Paman, U., S. Bahri, Asrol, and L. Liana. 2016. Distribution and Use Patterns of SmallScale Rice Mills in Kampar Regency, Riau Province, Indonesia. International Journal of Advanced Science Engineering Information Technology, 6(2): 149-152.

Verma, M, and A. Tripathi. 2016. Perspective of the Status of Agricultural Mechanization in the Bihar State. International Journal of Emerging Technology \& Research, 3(3): 10-17. 
